\title{
Practical Considerations When Using Fiber Optics for Dissolution Testing
}

\author{
Martin Wunderlich ${ }^{1}$, Terry Way ${ }^{2}$, Jennifer B. Dressman ${ }^{1,3}$
}

email:Dressman@em.uni-frankfurt.de

\section{Introduction}

r he UV fiber optics system has emerged in dissolution testing of solid dosage forms as a useful alternative to conventional dissolution tests in both research \& development and quality control. The system allows continuous in situ analysis of the drug concentration without the need for sample withdrawal and preparation. Therefore, this technique not only facilitates automation, but also eliminates potential errors in sample preparation. However, the fiber optic analysis itself possesses some sources of error. Several critical parameters, such as interferences with insoluble excipients and changes in hydrodynamics in the dissolution vessel with probe position have been thoroughly addressed by C. Schatz et al. [1].

In the first part of this study, the influence of the orientation of one-sided immersion probes (see figure 1) in the vessel was investigated. Stronger light scattering interferences on the dissolution results could be expected when the open side of the probe faces the flow direction, because the likelihood of insoluble excipients flowing into the light pathway is greater. In the second part of this study, interferences from air bubbles adhering to the immersion probe were evaluated. Without media deaeration, air bubbles might be formed during a dissolution test or while dipping the probe in the media.

A prednisolone 5-mg tablet formulation with a low drug to excipient ratio (drug content $<4 \%$ $\mathrm{m} / \mathrm{m}$ ) was chosen for these studies.

\section{Materials and Methods \\ Materials}

Commercially available 5-mg Prednisolone tablets (Galenpharma GmbH Kiel, Germany, Lot 01362) were used for this study. Prednisolone refer-

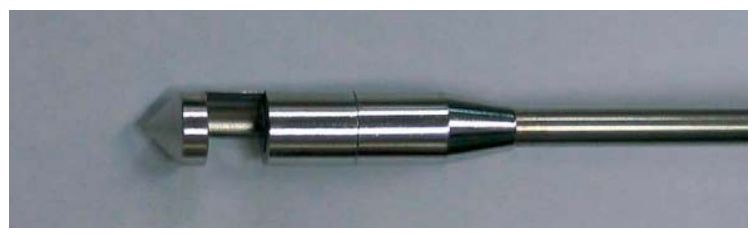

Figure 1: One-sided immersion probe (C-Technologies) ence standard was purchased from Caelo Hilden, Germany (Lot 43772494). All other chemicals were analytical grade and purchased commercially.

\section{Dissolution tests}

A Varian IO fiber optic dissolution system was used for all dissolution studies. The system, consisting of a USP II VanKel 7020 dissolution tester and a Cary 50 photometer, combined with a Cassini multiplexer and fiber optic probes, was provided by Varian (Walnut Creek, CA, USA) and C-Technologies (Cedar Knolls, NJ, USA). The system was controlled by Cary WinUV Fiber Dissolution application software, which was configured to measure the drug absorption at $246 \mathrm{~nm}$ with a matrix compensation at $401 \mathrm{~nm}$.

The dissolution studies were performed according to the USP 26 monograph "Prednisolone Tablets" [2], with $\mathrm{n}=6$.

\section{Profile accuracy}

Parallel to the fiber optic analysis, manual samples were withdrawn and analyzed off-line using a V3000 spectrophotometer (Hitachi, Japan). The samples were withdrawn using a Fortuna Optima glass syringe (Fischer Labortechnik, Frankfurt/Main, Germany) fitted with a stainless steel cannula. The tip of the cannula was fitted with a 10$\mu \mathrm{m}$ frit to prevent undissolved material from being withdrawn from the vessel. The sampling location in the dissolution vessel conformed to USP 26 guidelines [2]. The dissolution profiles from the two methods were compared using the $f_{2}$ test [3]. Note, that the $f_{2}$-test was applied to the entire dissolution profile and, for this and other reasons, did not conform to standard FDA $f_{2}$-test criteria $(n=12$, $<20 \%$ coefficient of variation at earlier time points, maximum one time point with $>85 \%$ dissolution) [4]. The parameters of the dissolution test are shown in Table 1.

\section{Probe position study}

Fiber optic dissolution tests were performed with three different, fixed probe positions (see Figure 2) and random positioning of the probes. The dissolution profiles were compared by calcu-

2 Varian Ltd, 28 Manor Road, Walton-on-Thames, Surrey KT12 2QF England 3 Corresponding author, email:Dressman@em.uni-frankfurt.de
1 Department of Pharmaceutical Technology, J. W. Goethe University, Marie Curie Str. 9, 60439 Frankfurt am Main, Germany 


\section{Practical Considerations When Using Fiber Optics ... continued}

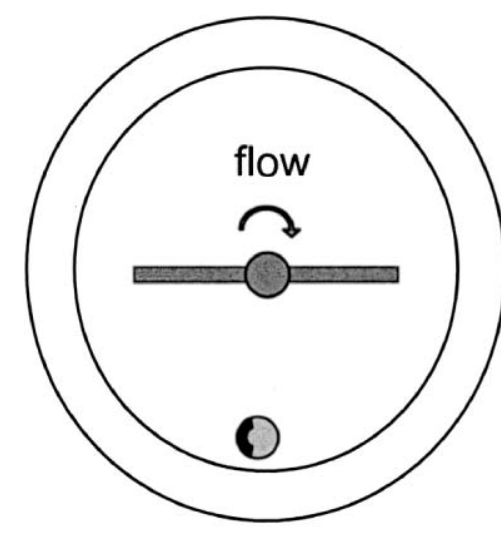

Position 1

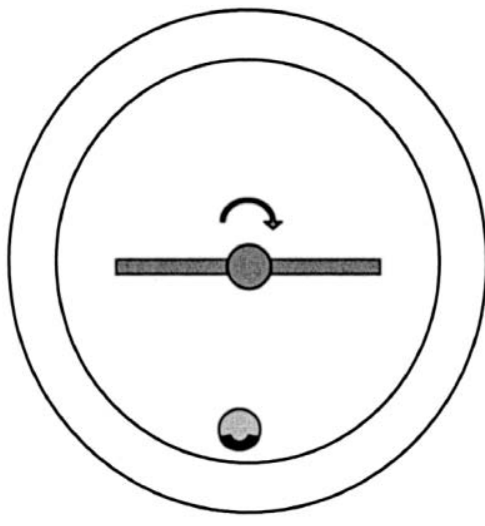

Position 2

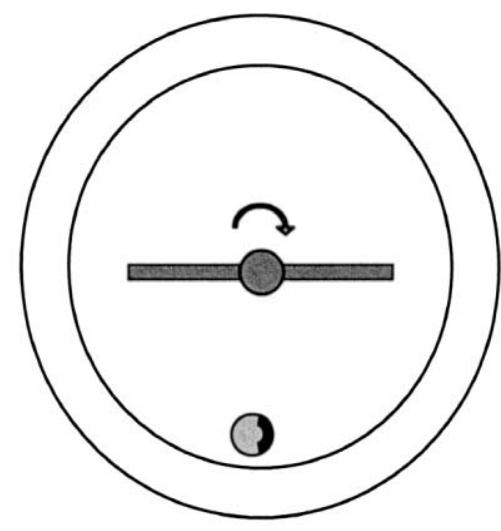

Position 3

Figure 2: Varying immersion probe orientations in the dissolution vessel (top view)

Table 1: Dissolution test parameters

\begin{tabular}{|c|c|c|c|c|c|}
\hline Test & Media and volume & Speed & Test duration & Sampling interval & Path length \\
\hline Profile accuracy & Deaerated water $900 \mathrm{ml}$ & $50 \mathrm{rpm}$ & $60 \mathrm{~min}$ & $15 \mathrm{~min}$ & $10 \mathrm{~mm}$ \\
\hline Probe position study & Deaerated water $900 \mathrm{ml}$ & $50 \mathrm{rpm}$ & $60 \mathrm{~min}$ & $15 \mathrm{~min}$ & $10 \mathrm{~mm}$ \\
\hline \multirow{2}{*}{$\begin{array}{l}\text { Air bubble } \\
\text { interference study }\end{array}$} & Untreated water $900 \mathrm{ml}$ & $50 \mathrm{rpm}$ & $60 \mathrm{~min}$ & $5 \mathrm{~min}$ & $10 \mathrm{~mm}$ \\
\hline & Deaerated water $900 \mathrm{ml}$ & $50 \mathrm{rpm}$ & $60 \mathrm{~min}$ & $5 \mathrm{~min}$ & $10 \mathrm{~mm}$ \\
\hline
\end{tabular}

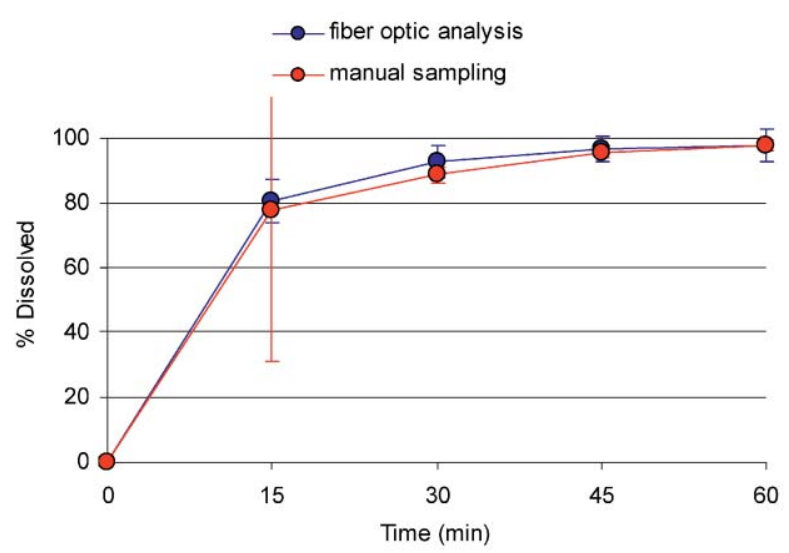

Figure 3: Dissolution profile of 5-mg Prednisolone tablets in water: fiber optic analysis versus manual sampling $(n=6, \pm S D)$

Table 2: $F_{2}$ values for the profiles obtained with probe positions 1, 2 and 3 compared to random probe position

\begin{tabular}{|lccc|}
\hline Probe position: & Position $\mathbf{1}$ & Position $\mathbf{2}$ & Position $\mathbf{3}$ \\
\hline $\mathrm{f}_{2}$ value: & 84 & 71 & 65 \\
\hline
\end{tabular}

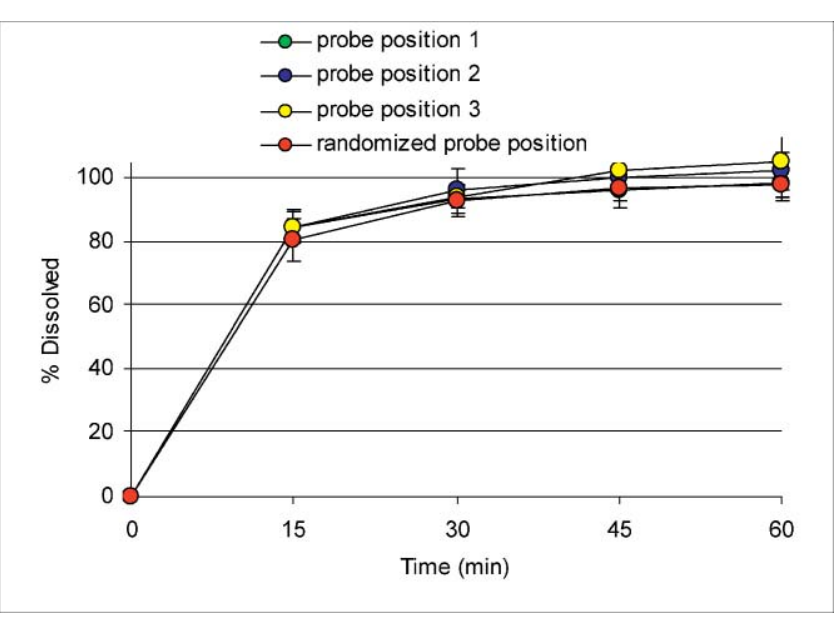

Figure 4: Influence of the probe orientation on the dissolution profile of 5-mg Prednisolone tablets $(n=6, \pm S D)$

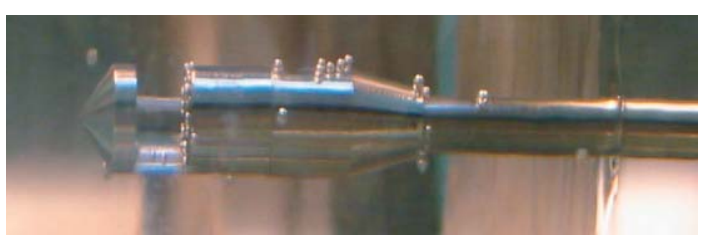

Figure 5: Air bubbles adhering to the immersion probe in untreated media 


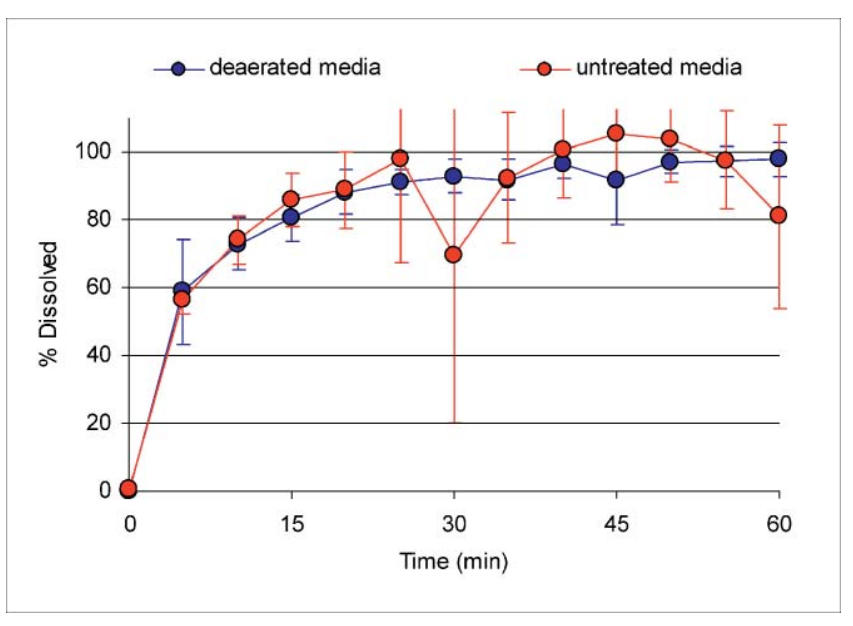

Figure 6: Fiber optic analysis of 5-mg Prednisolone tablets in deaerated versus untreated media $(n=6, \pm S D)$

lating the $\mathrm{f}_{2}$ value (see above). Dissolution test parameters are displayed in Table 1.

\section{Study of interference by air bubbles}

In this study, two dissolution tests of identical design were performed with fiber optics, in deaerated media and in untreated media, to evaluate the influence on the dissolution profile of air bubbles formed on the probes. The dissolution test parameters are shown in Table 1.

\section{Results}

\section{Accuracy of the fiber optic method}

The results of the profile accuracy study are illustrated in Figure 3. Fiber optic and off-line analysis lead to comparable results. The calculated $f_{2}$ value is 78 .

\section{Influence of the probe position on fiber optic analysis}

Various probe positions were used to determine whether differences in probe orientation would affect the dissolution process. No obvious change in the concentration/time profile was observed (Figure 4). A statistical comparison of the dissolution profiles with the $f_{2}$ test did not show any significant differences between the profiles (see Table 2).

Based on these results, it can be concluded that the probe orientation in the vessel plays at most a minor role in the fiber optic analysis.

\section{Influence of air bubbles on the fiber optic analysis}

For this study, the formation of air bubbles was evaluated by comparing dissolution profiles in deaerated and untreated media. Throughout the dissolution test in untreated media, the formation of air bubbles on the immersion probes was observed (see Figure 5). Figure 6 shows the mean dissolution profiles in deaerated and untreated media. The air bubbles lead to serious interferences in the fiber optic analysis, as can be seen by the erratic profile and the much higher standard deviations in the concentration/time values of the untreated media profile. The average coefficient of variation was $8.4 \%$ for the dissolution in deaerated versus $20.8 \%$ for the dissolution in untreated media.

\section{Conclusion}

Two practical concerns associated with the use of fiber optics in dissolution testing are the positioning of the probe and the influence of air bubbles on the results. This study demonstrated clearly that the orientation of the probe in the vessel has little or no effect on the profile, whereas air bubbles lead to undesirable variability in the data. The latter problem is effectively addressed by properly degassing the media.

\section{Acknowledgements}

The experimental work was performed by a group of pharmacy students at the JWG University, Frankfurt Germany:Christian Birli, Christina Förster, Melanie Hendricks, Sabine Kremer, David Stein and Gabriele Tomasino, under supervision of Martin Wunderlich and Jennifer B. Dressman. The authors would like to acknowledge the contributions of Ishai Nir to these studies.

\section{References}

1. Schatz, C., et al., Thoughts on fiber optics in dissolution testing, Dissolution Technologies, 2001. 8(2): p. 6-11.

2. USP 26-NF 21, ed. U.S.P. Convention. 2003, 12601 Twinbrook Parkway, Rockville, Maryland 20852, USA.

3. Moore, J.W. and H.H. Flanner, Mathematical comparison of dissolution profiles. Pharmaceutical Technology, 1996. 20(6): p. 64-74.

4. Dissolution testing of immediate release solid oral dosage forms. FDA Guidance for industry, 1997. 